\title{
Е.В. Морозова
}

\section{МУЗЕЙНАЯ ПОЛИТИКА КАК НАУЧНОЕ ПОНЯТИЕ В МУЗЕОЛОГИИ}

\begin{abstract}
Статья посвящена проблеме формирования понятия «музейная политика». Анализ зарубежной и российской музееведческой литературы позволяет определить содержание этого понятия и выявить его составляющие: музейный менеджмент, музейный маркетинг, государственная политика в области культуры, миссия музея. В результате проведенного исследования выясняются смысловые изменения понятия «музейная политика» как адекватного отражения музеологической реальности.

Ключевые слова: музеология, музейная политика, музейный маркетинг, музейный менеджмент, миссия музея.
\end{abstract}

Становление любой науки тесно связано с формированием ее понятийного аппарата. По мере развития в фокусе внимания исследователей появляются новые термины, вводимые для объяснения сущности объектов и явлений в данной области знаний. В музеологии как комплексе научных дисциплин идет процесс активного формирования понятий, отражающих те или иные направления и виды музейной деятельности (в частности, музейная политика).

Анализ музеологических работ, изданных в Великобритании, Канаде и США, показал, что в отношении музея в них применяются термины policy и politics, что на русский язык переводится как политика. Первый из этих терминов - policy - используют в своих работах Э. Хупер-Гринхилл, Р. Сандел, С. Эшли, подразумевая под ним планы, направления, технологии функционирования музея, изложенные в специальных документах $[1,2,3]$. Так, Э. Хупер-Гринхилл сообщает, что политика музея включают в себя коммуникационную политику, стратегии развития, планы конкретных действий, а также маркетинговую политику, выставочную политику, образовательную политику и политику заботы о посетителях [1. Р. 173]. В качестве примера на сайтах крупных музеев Великобритании, Канады и США можно найти раздел с названием «Policy», в котором раскрываются различные виды музейной деятельности (политика управления коллекциями, политика консервации, маркетинговая политика, политика исследований, выставочная политика).

В трудах Т. Беннетта, Т. Люка и С. Эсмил-Памис можно встретить также понятие museum politics, которое отражает возрастающую роль музея, его способность воздействовать на аудиторию посредством трансляции определенной информации $[4,5,6]$. Так, Т. Беннетт считает, что уже в XIX в. в правящих кругах Великобритании утвердилось мнение о необходимости использовать музей как инструмент влияния на общество и обеспечения контроля государства над своими гражданами. Опираясь на концепцию «власть знания», сформулированную М. Фуко, английский исследователь утверждает, что музей позволяет человеку знать, учиться и получать опыт быть гражда- 
нином. В этом постулате находят отражения такие функции музея, как документирование (владение знанием), образование (обучение) и воспитание (опыт гражданственности) [4. Р. 19.].

Рассматриваемый термин начинает входить в употребление в отечественной научной литературе. Однако прежде чем обратиться к российским музеологическим изысканиям, необходимо еще раз акцентировать внимание на том, что эквивалентом двух английских слов policy и politics служит одно русское слово политика. И если в англоязычной литературе разное смысловое ядро понятий отражено в наличии разных терминов, то российские музеологи вкладывают различные смыслы в один термин «музейная политика». Так, в статье А.И. Фролова данное словосочетание используется для обозначения политики государства в области музейного дела. Автор, имея в виду государственную политику по отношению к музеям, пишет, что «сказанного достаточно для осознания потребности в разработке и научном обосновании новой музейной политики, отвечающей курсу перестройки» [7. С. 33]. В работе В.Ю. Дукельского понятие «музейная политика» отражает государственную культурную политику, которая реализуется непосредственно музейными учреждениями на местах [8]. Авторы «Словаря актуальных музейных терминов» дают наиболее полное определение музейной политики как совокупности принципов и методов управления музеем, нацеленных на осуществление миссии музея и обеспечение выполнения им социальных функций музея [9. С. 67].

Другие исследователи используют в своих работах отдельные составляющие понятия «музейная политика». Так, Ю.В. Зиновьева касается термина «стратегии музейной коммуникации» и понимает его как некие принципы, регулирующие отношения музея с окружающей средой и обществом [10]. Это толкование очень близко по смыслу к одному из значений англоязычного термина «museum policy», а именно к коммуникационной музейной политике в работе Э. Хупер-Гринхилл.

Е.С. Соболева и М.З. Эпштейн большое внимание уделяют развитию музея в современных экономических условиях, поэтому основой в управлении музеем считают маркетинговые технологии. В связи с этим они используют термин «музейная политика» в сочетании с прилагательными «товарная» и «рыночная», выделяют «ценовую политику», «коммуникационную и конкурентную политику», а в качестве синонима слова «политика» используют термины «стратегия» и «концепция развития» [11]. Схожие словосочетания «стратегическое планирование» и «стратегическое управление» - использует Л.Е. Востряков для обозначения работы топ-менеджеров, заключающейся в решении важных вопросов в управлении музеем и планировании его деятельности [12]. При этом исследователь поясняет, что стратегическое планирование представляет собой совокупность программ, принципов, методов и приемов, используемых для управления музеем. Отметим сходство этой формулировки с определением, данным в «Словаре актуальных музейных терминов».

Н.В. Нагорский в своем фундаментальном исследовании «Музей в духовной жизни общества» определяет в качестве наиболее важной культурообразующую составляющую музейной работы, называет ее одной из ведущих 
функций современного музея. Он вводит в научный оборот понятие «культурная политика музея», под которым понимает совокупность концептуальных положений, принципов и направлений музейной деятельности. По мнению исследователя, культурная политика музея обеспечивает реализацию созидающего потенциала культуры, способствует концентрации усилий на приоритетных направлениях ее развития, сохраняет национально-культурное наследие, стимулирует социально-культурную активность населения, привлекает музей к осуществлению национальных, региональных, муниципальных и отраслевых культурных программ, поддерживает диалог культур и международные культурные связи, совершенствует инфраструктуру социально-культурной сферы посредством музеефикации памятников истории и культуры, а также помогает в подготовке специалистов, владеющих современными технологиями музейного дела [13. С. 198-199].

Итак, обращение к работам отечественных исследователей показывает, что смысловое содержание понятия «музейная политика» раскрывается в них через такие понятия, как «культурная политика музея», «музейный менеджмент», «музейный маркетинг», «стратегии развития музея», «музейное проектирование и планирование», «концепция развития». В отдельных публикациях они могут выступать в качестве синонимов музейной политики или как ее компоненты. В связи с этим рассмотрим научные термины, наиболее близкие по своему значению к понятию «музейная политика».

Появление терминов «музейный менеджмент» и «музейный маркетинг» было связано с адаптацией музеев к условиям рыночной экономики, когда актуальным стало не только изучение музеями своих посетителей, но и понимание важности планирования деятельности с целью поддержания своего существования и обеспечения дальнейшего развития. Под музейным маркетингом понимается деятельность музея по определению, предвидению и удовлетворению потребностей разных групп населения, оказанию влияния на музейную аудиторию, а также организация сбыта музейного продукта [11. C. 10]. В некоторых работах утверждается, что маркетинг - залог успешной деятельности современного музея, он обеспечивает выживание и успешное функционирование музея в условиях рыночной экономики [14]. Входящие в компетенцию музейного маркетинга аналитическая работа, а также функции управления и контроля, которые реализуются посредством организации системы коммуникации и деятельности по связям с общественностью, тесно связаны с планированием, что позволяет некоторым исследователям ставить знак равенства между понятиями «музейный маркетинг» и «музейная политика». Такой знак, уравнивающий два понятия, ставят Е.С. Соболева и М.3. Эпштейн в статье «Маркетинговая политика музеев Швейцарии накануне нового тысячелетия». При этом в работе рассматриваются некоторые составляющие музейной политики - экспозиционная политика, выставочная политика и др. [15]. Принимая точку зрения иностранных авторов, например Э. Хупер-Грнхилл, о маркетинговой политике как подразделе музейной политики, отметим, что, на наш взгляд, музейный маркетинг интересуют в основном проблемы взаимодействия музея с посетителем, а все другие виды деятельности он затрагивает настолько, насколько они связаны с реализацией работы с музейной аудиторией. При этом акцент делается на 
изучении потребностей посетителя и их удовлетворении, так как от того, насколько посетителю понравится в музее, будет зависеть, придет ли он в этот музей снова, расскажет ли о своем визите знакомым. Формирование интересов аудитории музея, таким образом, остается за пределами компетенции маркетинговой политики, а этот аспект является одной из целей музейной политики (в рамках работы с посетителем).

Для успешного функционирования музею необходимо планировать свою деятельность, составлять краткосрочные и долгосрочные планы работы, расставлять приоритеты. Этими вопросами призван заниматься музейный менеджмент как система знаний об управлении учреждением и его персоналом. Согласно Л.Е. Вострякову музейный менеджмент включает в себя различные инструменты: управление проектами и программами, музейный маркетинг, фандрейзинг, информационные управленческие технологии, PR и рекламу, управление персоналом, стратегическое управление и стратегическое планирование [12]. Подчеркивая значимость музейного менеджмента, С.А. Копацкая предлагает даже рассматривать музейную политику в рамках работы менеджера музея [16]. На наш взгляд, точки соприкосновения находятся в стратегическом планировании, которое, являясь составной частью музейного менеджмента, по смыслу близко к тому, что мы вкладываем в понятие «музейная политика».

Стратегия развития, стратегическое планирование - термины, которые, как было сказано, используются в музейном менеджменте. Под этими терминами понимается разработка определенного плана развития учреждения, его поэтапное движение к обозначенной цели. Стратегии предполагают тщательное изучение слабых и сильных сторон музея, возможных альтернатив развития, а также поиск новых партнеров. Очень многое зависит от доступных денежных средств, поэтому в музеях часто приходится делать выбор в пользу того или иного проекта или направления деятельности. Однако музей в своей деятельности должен не только ориентироваться на выгодное предоставление своих услуг, он является частью национального достояния и строит свою работу в соответствии с государственной политикой в области культуры. Ведь именно посредством музея реализуется один из пунктов Конституции РФ о праве граждан иметь доступ к культурным ценностям. Российские музеи, даже не находящиеся под непосредственным контролем государства, должны соответствовать культурным запросам граждан и, подчиняясь законодательству, следовать тем требованиям и ориентирам, которые дает государство в своей культурной политике. В качестве примера можно привести ставшее уже традицией посвящение очередного года какому-либо событию или культуре определенной страны - год Франции, Италии, Греции, год культуры, литературы, кино - находящее отражение в деятельности социокультурных институтов. В качестве инструментов влияния выступают также различные гранты, национальные и международные проекты, тематические конференции, которые задают вектор развития, в том числе и в работе современных музеев.

В последнее время за музеем все чаще признается роль самостоятельного социального агента. Именно музей предлагает вниманию посетителей наглядную картину мира и определенный взгляд на вещи (музейные предметы, составляющие экспозицию). Более того, музей, работая с разнообразными па- 
мятниками культурного наследия и имея в своем распоряжении современные технологии, способен усилить воздействие на аудиторию по линии конструирования смыслов, апеллируя к эмоциональному восприятию. Высокий воспитательный потенциал музея связан с его деятельностью по формированию культурной идентичности и трансляцией идей толерантности в современном мультикультурном мире. Все это включается в понятие миссии музея.

Нужно отметить, что идею, вложенную в понятие музея и сформулированную в рамках современной музеологии в виде его миссии, поддерживали многие отечественные и зарубежные мыслители (Н.Ф. Федоров, Ф.И. Шмит, П.А. Флоренский, Ж.А. Ривьер, Д. Рескин, Ж.-Л. Деот), считавшие главной задачей музея способствование благополучию общества. Эта идея нашла отражение в концепции новой музеологии, которая предполагает активную роль музея во взаимоотношениях с местным сообществом. Музей при этом не только заботится о сохранении культурного наследия, но и помогает решению социальных проблем. Опираясь на труды предшественников, можно определить миссию музея как сверхзадачу, как важнейшую цель функционирования социокультурного института, каким является музей. В нашем понимании миссия музея включает в себя четыре основополагающих цели: сохранение культурного наследия, формирование культурной идентичности, формирование мировоззрения и решение актуальных проблем местного сообщества.

Таким образом, мы можем говорить не только о тесной взаимосвязи музея и общества, но и о возможности этого общественного института участвовать в решении актуальных проблем, оказывать влияние на развитие социума в рамках осуществления своей миссии. Основу деятельности современного музея определяет сочетание гармоничной и продуманной работы всех отделов музея (музейный менеджмент) и его успешного функционирования в условиях рыночной экономики (музейный маркетинг) с осознанием ответственности перед обществом (реализация миссии музея) и соответствием проводимой государством политике в области культуры. С учетом всех внутренних возможностей и внешних условий формируются принципы развития музея, реализуются его функции, которые и отражает понятие «музейная политика».

\section{Лumepamypa}

1. Hooper-Greenhill E. Museums and their visitors. London; New York : Routledge, 1994. 206 p.

2. Ashley S. State Authority and the Public Sphere: Ideas on the Changing Role of the Museum as a Canadian Social Institution // Museum and society. 2005. №3 (1). P. 5-17.

3. Sandell R. Museums, Prejudice and the Reframing of Difference. London; New York : Routledge, 2007. 226 p.

4. Bennett T. The birth of the museum. History, theory, politics. London; New York : Routledge, 1996. $278 \mathrm{p}$.

5. Luke T.W. Museum politic : power plays at the exhibition. Minneapolis : University of Minnesota Press. 2002. 265 p.

6. Esmel-Pamies C. Into the Politics of Museum Audience Research. Tate Encounters, 2009. [Электронный ресурc]. URL: http://www2.tate.org.uk/tate-encounters/edition-5/Cinta-Esmel-PamiesInto-the-Politics-of-Museum-Research.pdf (дата обращения: 01.03.2016).

7. Фролов А.И. Советские музеи в зеркале прессы (по материалам периодической печати 1988 г.) // На пути к музею XXI века. М., 1989. С. 5-34. 
8. Дукельский В. Ю. Культурная политика и региональная специфика // Музей и регион / отв. ред. А.В. Лебедев. М., 2011. С. 11-35.

9. Музей: Словарь актуальных музейных терминов // Музей. 2009. № 5.68 с.

10. Зиновьева Ю.В. Стратегии коммуникации музея: 20 лет постсоветской трансформации // Вестн. СПбГУКИ, 2013. № 3 (16). С. 102-107.

11. Соболева E.C. Эволюция концепции музеев в меняющемся мире / Е.С. Соболева, М.3. Эпштейн // Вопросы музеологии. 2011. Вып. 1 (3). С. 8-19.

12. Востряков Л.Е. Современный музейный менеджмент // Экология культуры. Архангельск. 2004. № 3. С. 3-22.

13. Нагорский Н.В. Музей в духовной жизни общества. СПб., 2004. 427 с.

14. Раньярд $C$. Маркетинг как взаимодействие с аудиторией // Музейный менеджмент и маркетинг. М., 2001. С. 113-139.

15. Соболева E.C. Маркетинговая политика музеев Швейцарии накануне нового тысячелетия / Е.С. Соболева, М.З. Эпштейн // Триумф музея? СПб., 2005. С. 314-331.

16. Копацкая C.A. Управление музеем в рамках стратегии создания музейных комплексов : автореф. дис. ... канд. экон. наук. СПб., 2000. 18 с.

Morozova Elena V. Saint-Petersburg State Institute of Culture (Saint-Petersburg, Russian Federation).

E-mail: lenavmorozova@yandex.ru

Tomsk State University Journal of Cultural Studies and Art History, 2016, (3) 23, p. 180-186.

DOI:10.17223/22220836/23/19

SEMANTIC MATTER OF «MUSEUM POLICY» AS SCIENTIFIC NOTION

Key words: museum policy, museum marketing, museum management, museum mission, strategic planning.

The museology formation as branch of science actualizes its theoretical base including conceptual apparatus. As a result it is necessary to precise terms that were used in scientific literature recently. In this article semantic matter of the term "museum policy" is precised.

Analysis of scientific works in English and Russian languages shows that in English language researches different semantic content of scientific notions are corresponded to adequate terms (museum policy, museum politics). At the same time native scientists often see different meanings in the term "museum policy" or use terms which meanings are close in semantic matter to the term "museum policy": cultural museum policy, museum management, museum marketing, strategic planning, museum projecting and planning, the concept of development. In this connection in this paper the comparative analysis of semantic matter of these scientific notions is performed.

Museum marketing's gain is to support museum "viability" and its competitive ability among other institutes of entertainment industry. The main task of museum marketing is a research of museum auditorium, its interests and demands.

Museum marketing is usually suggested as a part of museum management that is occupied with administration and coordination of functioning of all museum departments. The important part of museum management is to conceive long-term, medium-term and current plans. Strategic planning and strategic administration contain studying of strengths and weaknesses and probable development, searching for new partners, working out and consideration of most profitable for the institute projects.

Nevertheless museum is not confined by the institute interests and cultural demands of society but also depends on Culture Legislation - satisfies requirements and a guiding line of the state cultural policy.

Museums with their large educational and pedagogic potential must realize their responsibility to society and fulfill their purpose that embodied in the idea of a mission. We suggest that museum mission consists of four main aims: saving cultural heritage, forming cultural identity, forming world view and solving actual problems of local community. Museum mission can be defined as the most important task, the aim of museum as a social and cultural institute.

Thus definition "museum policy" contains balanced and considered work of all museum departments (museum management) and its successful functioning in conditions of market economy (museum marketing), realizing responsibility to society (realization of museum mission) and satisfying a guiding line of the state cultural policy. 


\section{References}

1. Hooper-Greenhill, E. (1994) Museums and their visitors. London; New York: Routledge.

2. Ashley, S. (2005) State Authority and the Public Sphere: Ideas on the Changing Role of the Museum as a Canadian Social Institution. Museum and society. 3(1). pp. 5-17.

3. Sandell, R. (2007) Museums, Prejudice and the Reframing of Difference. London; New York: Routledge.

4. Bennett, T. (1996) The birth of the museum. History, theory, politics. London; New York: Routledge.

5. Luke, T.W. (2002) Museum politic : power plays at the exhibition. Minneapolis: University of Minnesota Press.

6. Esmel-Pamies, C. (2009) Into the Politics of Museum Audience Research. [Online] Available from: http://www2.tate.org.uk/tate-encounters/edition-5/Cinta-Esmel-Pamies-Into-the-Politics-ofMuseum-Research.pdf. (Accessed: 1st March 2016).

7. Frolov, A.I. (1989) Sovetskie muzei v zerkale pressy (po materialam periodicheskoy pechati 1988 g.) [Soviet museums in the mirror of the press (on materials of the periodical press of the 1988s)]. In: Maystrovskaya, M.T. (ed.) Na puti $k$ muzeyu XXI veka [On the way to the museum of the 21st century]. Moscow: Moscow Institue of Culture. pp. 5-34.

8. Dukelskiy, V.Yu. (2011) Kul'turnaya politika i regional'naya spetsifika [Cultural policy and regional specificity]. In: Lebedev, A.V. (ed.) Muzey i region [Museum and Region]. Moscow: Russian Institute of Culture Studies. pp. 11-35.

9. Anon. (2009) Muzey: Slovar' aktual'nykh muzeynykh terminov [Museum: Glossary of modern terms]. Muzey. 5.

10. Zinoveva, Yu.V. (2013) Strategii kommunikatsii muzeya: 20 let postsovetskoy transformatsii [Museum Communication Strategies: 20 years of post-Soviet transformation]. Vestn. SPbGUKI. 3(16). pp. 102-107.

11. Soboleva, E.S. \& Epstein, M.Z. (2011) Evolyutsiya kontseptsii muzeev v menyayushchemsya mire [The evolution of museum concepts in a changing world]. Voprosy muzeologii - The Problems of Museology. 1(3). pp. 8-19.

12. Vostryakov, L.E. (2004) Sovremennyy muzeynyy menedzhment [Modern museum management]. Ekologiya kul'tury. 3. pp. 3-22.

13. Nagorskiy, N.V. (2004) Muzey v dukhovnoy zhizni obshchestva [Museum in the spiritual life of society]. St. Petersburg: [s.n.].

14. Ranyard, S. (2001) Marketing kak vzaimodeystvie s auditoriey [Marketing as the interaction with the audience]. In: Muzeynyy menedzhment $i$ marketing [Museum management and marketing]. Moscow: [s.n.]. pp. 113-139.

15. Soboleva, E.S. \& Epstein, M.Z. (2005) Marketingovaya politika muzeev Shveytsarii nakanune novogo [ES Marketing policy of museums in Switzerland on the eve of the new millennium]. In: Nikonnov, A.A. (ed.) Triumf muzeya? [Triumph of the Museum?]. St. Petersburg: St. Petersburg Hermitage. pp. 314-331.

16. Kopatskaya, S.A. (2000) Upravlenie muzeem v ramkakh strategii sozdaniya muzeynykh kompleksov [Running a Museum in the strategy of creating museum complexes]. Abstract of Economics Cand. Diss. St. Petersburg. 